\title{
La resección prostática transuretral permanece como tratamiento quirúrgico estándar para la hiperplasia prostática benigna
}

Transuretral prostatic resection remains as the standard surgical treatment for benign enlargement of the prostate

Lourenco T y col. BMJ 2008; 337; a449.

\section{Objetivo}

Comparar la efectividad y los efectos adversos de los métodos endoscópicos de ablación prostática mínimamente invasivos, con el tratamiento quirúrgico estándar para hiperplasia prostática benigna (HPB): la resección prostática transureteral (RTU-P).

\section{Fuentes de datos y selección de estudios}

Luego de una búsqueda en registros electrónicos de publicaciones hasta 2006, dos revisores evaluaron y seleccionaron en forma independiente todos los estudios controlados y aleato- rizados que hubieran comparado nuevas alternativas quirúrgicas contra la RTU-P.

\section{Resultados}

45 estudios de moderada a pobre calidad (3970 pacientes) cumplieron los criterios de inclusión.

A los 12 meses todas las intervenciones se asociaron a una mejoría sintomática, con una tendencia favorable a RTU-P; mientras que la mejoría en la uroflujometría fue significativamente mayor para la RTU-P. Ver tabla 1.

Tabla 1: resultados comparativos a los 12 meses entre las nuevas tecnologías y la resección prostática transuretral (RTU-P).

\begin{tabular}{|c|c|c|c|c|c|c|}
\hline & \multicolumn{2}{|c|}{$\begin{array}{l}\text { Diferencia (IC95\%) en la eficacia } \\
\text { con la RTU-P }\end{array}$} & \multicolumn{4}{|c|}{$\begin{array}{l}\text { Riesgo relativo (IC95\%) de complicaciones } \\
\text { (RR=1 para la RTU-P) }\end{array}$} \\
\hline & $\begin{array}{l}\text { Puntaje de } \\
\text { sntomas }^{2}\end{array}$ & $\begin{array}{c}\text { Pico flujo } \\
\text { urinario }\end{array}$ & $\begin{array}{c}\text { Tranfusiones } \\
\text { de sangre }\end{array}$ & $\begin{array}{c}\text { Retención } \\
\text { urinaria }\end{array}$ & $\begin{array}{l}\text { Pérdidia de la } \\
\text { eyaculación }\end{array}$ & $\begin{array}{l}\text { Necesidad de } \\
\text { reoperación }\end{array}$ \\
\hline $\begin{array}{l}\text { Resección transuretral con } \\
\text { microondas }\end{array}$ & $\begin{array}{c}+2,26 \\
(-0,98 \text { a } 4,91)\end{array}$ & $\begin{array}{c}-5,08 \mathrm{~mL} / \mathrm{min} \\
(-8,32 \mathrm{a}-1,83)\end{array}$ & $\begin{array}{c}0,11 \\
(0,01 \text { a } 1,98)\end{array}$ & $\begin{array}{c}1,64 \\
(0,77 \text { a } 3,05)\end{array}$ & $\begin{array}{c}0,39 \\
(0,25 \text { a } 0,59)\end{array}$ & $\begin{array}{c}2,01 \\
(0,96 \text { a } 4,18)\end{array}$ \\
\hline $\begin{array}{c}\text { Ablación transuretral con } \\
\text { aguja }\end{array}$ & $\begin{array}{c}+3,99 \\
(1,27 \text { a } 6,53)\end{array}$ & $\begin{array}{c}-9,04 \mathrm{~mL} / \mathrm{min} \\
(-14,68 \text { a }-3,40)\end{array}$ & $\begin{array}{c}0,05 \\
(0,01 \text { a } 0,32)\end{array}$ & $\begin{array}{c}1,48 \\
(0,47 \text { a } 4,52)\end{array}$ & $\begin{array}{c}0,08 \\
(0,03 \text { a } 0,17)\end{array}$ & $\begin{array}{c}6,89 \\
(1,98 \text { a } 29,95)\end{array}$ \\
\hline $\begin{array}{l}\text { Coagulación } \\
\text { con laser }\end{array}$ & $\begin{array}{c}+3,01 \\
(1,06 \text { a } 7,07)\end{array}$ & $\begin{array}{c}-5,05 \mathrm{~mL} / \mathrm{min} \\
(-9,86 \text { a }-1,13)\end{array}$ & $\begin{array}{c}0,11 \\
(0,04 \text { a } 0,26)\end{array}$ & $\begin{array}{c}2,31 \\
(1,11 \text { a } 4,08)\end{array}$ & $\begin{array}{c}0,22 \\
(0,14 \text { a } 0,35)\end{array}$ & $\begin{array}{c}3,21 \\
(1,65 \text { a } 6,24)\end{array}$ \\
\hline
\end{tabular}

${ }^{a}$ Cuestionario del Score Sintomático Internacional de la Asociación Americana de Urología con puntajes de 0 a 35 en el que 0 a 7 puntos implican síntomas leves; 8 a 19, síntomas moderados y 20 a 35, síntomas severos.

Las necesidades de transfusión sanguínea fueron menores para los métodos laser sobre la RTU-P $(0,7 \%$ vs $4,8 \%)$. La estrechez de uretra fue menor para los métodos alternativos, lo mismo que la incontinencia excepto para la resección transuretral con microondas; sin diferencias ente los distintos métodos para la incidencia de infecciones del tracto urinario. El tiempo de internación fue un promedio de 24 horas menor en los sometidos a métodos alternativos.

\section{Conclusiones}

Debido a la pobreza de la evidencia encontrada y las grandes diferencias en los resultados de las terapias alternativas, la RTU-P sigue siendo el tratamiento estándar para la HPB.

Palabras claves: resección prostática transuretral, hiperplasia prostática benigna, revisión sistemática.

Key words: transuretral prostatic ablation, benign prostatic hypertrophy, systematic review. Fuente de financiamiento: Health Technology Assessment programme.

\section{Comentario}

La HPB es una condición ligada al avance de la edad' que afecta al $30 \%$ de los mayores de 65 años $^{2}$ y no produce riesgo de vida pero afecta la calidad de la misma. Cuando no hay respuesta a los tratamientos médicos y si los síntomas lo justifican, se decide la conducta quirúrgica ${ }^{3}$. Los tratamientos clásicos son la RTU-P y la prostatectomía a cielo abierto, dependiendo la decisión entre ambas del tamaño prostático y de las preferencias del urólogo. La limitante es el tiempo de resección para las próstatas grandes ya que cirugías prolongadas aumentan el riesgo de síndrome de absorción del líquido de irrigación (o "post RTU") y su consecuencia más temida: la insuficiencia renal aguda por hemólisis. Las nuevas alternativas no necesitan de agua de irrigación (hipo osmolar) sino de solución fisiológica, disminuyendo así el riesgo de síndrome post RTU y permitiendo cirugías prolongadas.
Vale aclarar que este metaanálisis favorable a la RTU-P incluyó básicamente pacientes con próstatas de bajo volumen (un promedio de 30 a $70 \mathrm{~g}$ ) en quienes el tiempo operatorio no sería una limitante para la RTU-P; y que los métodos "laser" implican una curva de aprendizaje muy extensa para el urólogo4.

\section{Conclusiones del comentador}

La RTU-P puede realizarse con el equipamiento básico de cualquier servicio de urología. Si bien requieren menor tiempo de internación e implican menor sangrado, las nuevas tecnologías son de difícil acceso y mas costosas. Su desafío es lograr resecar próstatas superiores a 100g por vía endoscópica y así disminuir las indicaciones de las cirugías a cielo abierto.

Leandro Dourado [ Servicio de Urología del Hospital Italiano San Justo. leandro.dourado@hospitalitaliano.org.ar ]

Dourado L. La resección transuretral de próstata permanece como tratamiento estándar para la hiperplasia prostática benigna. Evid Act Pract Ambul. 12(1):12. Ene-Mar, 2009. Comentado de: Lourenco $\mathbf{T}$ y col. Alternative approaches to endoscopic ablation for benign enlargement of the prostate: systematic review of randomized controlled trials. BMJ 2008; 337; a449. doi:10.1136/bmj.39575.517674.BE PMID 17592479. Disponible en URL: http://www.bmj.com/cgi/reprint/337/jun30_1/a449

Referencia

1. Chute $C$ y col. The prevalence of prostatism: a population based survey of urinary symptoms. J Urol 1993;150(1):85-89.

2. Chapple C y col. BPH desease management. Eur Urol 1999; 36(Suppl 3): 1-6.

3. Borboroglu P y col. Immediate and postoperative complications of transurethral prostatectomy in de 1990s. J Urol 1999; 162(4): $1307-1310$.

4. Gilling P y col. Combination Holmium and Nd: YAG laser ablation of the prostate: initial clinical experience. J Edourol 1995;9(2):151-153. 